\title{
ПРОБЛЕМЫ ИМПОРТОЗАМЕЩЕНИЯ В ИНФОРМАЦИОННЫХ СИСТЕМАХ
}

\author{
УДК 061.3:681.3.06
}

\section{Юрий Алексеевич Лямин,}

к.т.Н., С.н.С., начальник научно-методического отдела ФГБУ НИИ "Восход" Тел.: (495) 9818899 доб. 15-61

Эл. почта: j.lyamin@voskhod.ru

В статье рассматриваются проблемы, возникающие при решении задачи импортозамещения в информационных системах, работающих в интересах государственных органов власти. Сформулированы задачи импортозамещения в сфере информационных технологий. Проанализированы исторически причины возникновения проблемы. Предложены возможные пути решения проблемы.

Ключевые слова: импортозамещение, инфоормационные технологии, территориально-распределенные инфоормационные системы, технологическая независимость.

\section{Yuri A. Lyamin}

$\mathrm{PhD}$ in Information Science, Associate Professor Head of Scientific and Methodical Department R\&D Institute "Voskhod"

Tel.: (495) 9818899 доб. 15-61

E-mail: j.lyamin@voskhod.ru

In the article the problems arising when solving the problem of import substitution in information systems, working in the interests of public authorities. Formulated the problem of import substitution in the field of information technology. Historically, analyzed the causes of the problem. Proposed possible solutions to the problem.

Keywords: import substitution, information technology, geographically-distributed information systems, technological independence.

\section{1. Введение}

В последние два года термин «импортозамещение» стал одним из самых распространенных терминов в публикациях и выступлениях, независимо от того, в какой сфере деятельности трудится автор.

Классическое определение импортозамещения:

Импортозамещение представляет собой замену иностранных товаров на продукцию отечественного производства. Способствует созданию дополнительных рабочихмест, стимулирует появление новых компаний и предпринимателей в сегменте среднего и малого бизнеса.

Согласно постановлениям правительства РФ, под действие программы по импортозамещению попадают такие отрасли, как

- сельское хозяйство;

- энергетическая отрасль, включающая предприятия ядерной-, топливной- и электроэнергетической промышленности;

- промышленная сфера, включающая станкоинструментальную, авиационную, автомобильную промышленность;

- некоторые другие отрасли, на которые повлияло введение санкций в 2014 году.

Для вышеперечисленных отраслей сформулированное выше определение применимо, но для ИТ-сферы это определение требует существенных уточнений. Связано это с тем, что основной целью импортозамещения в ИТ-сфере является обеспечение реальной технологической независимости России. Это в полной мере относится к создаваемым территориально распределенным информационным системам (ТРИС), разрабатываемых в интересах органов государственной власти.

\section{2. Проблема импортозамещения и уроки истории}

Не секрет, что большинство существующих ТРИС базируется на инфраструктурных элементах зарубежного производства, включая аппаратные и программные средства. И первоочередная задача импортозамещения - это обеспечение надежного функционирования существующих ТРИС в условиях возможного и вероятного противодействия со стороны предполагаемых оппонентов. На это, в основном, направлены решения, предлагаемые министерствами и ведомствами, ответственными за проблему импортозамещения.

Однако, это тактическое решение, рассчитанное на весьма короткий период (2-3 года). Вопрос создания новых и модернизации существующих ТРИС должен решаться на более долгосрочный период (10-15 лет). Связано это с целым рядом причин, одной из которых является необходимость формирования кадрового ресурса профессионалов ИТ-сферы. В качестве примера, вспомним ситуацию, с которой наша страна столкнулась 50 лет назад в ИТ-сфере. В тот период времени, существовала достаточно мощная радиопромышленность, которая производила практически все компоненты вычислительной техники. Некоторые ЭВМ (например, БЭСМ-6) по своим характеристикам опережала западные образцы. Однако, общее состояние вычислительного парка отличалось разнородностью и полной программной несовместимостью на уровне объектных кодов. Обеспечить массовую подготовку специалистов в ИТ-сфере, которые были необходимы стране, в этих условиях было невозможно. Поэтому было принято решение, по которому у специалистов до сих пор нет однозначного мнения.

Вместо выбора базовых направлений развития и ведущих разработчиков для основных классов ЭВМ (мейнфреймы, мини-ЭВМ и технологические ЭВМ) из числа отечественных конструкторов, было принято решение базироваться на «позаимствованных» образцах зарубежного производства, получивших широчайшее распространение в западных странах. Для этих 
целей были развернуты специальные институты, конструкторские бюро, начата массовая программа подготовки программистов и специалистов по эксплуатации «позаимствованных» аналогов импортных ЭВМ, в ущерб подготовке и обучению конструкторов и программистов для отечественных моделей. Так, например, разработчики программного обеспечения одной из лучших ЭВМ среднего класса Минск-32 получили Ленинскую премию (высшую награду для ученых во времена (ССР), и через полгода дальнейшее производство этих ЭВМ было свернуто и заменено на «заимствованную» серию ЕС ЭВМ.

Можно сказать, что именно в этот момент началось «импорто-внедрение» в ИТ-сфере. При этом, процесс заимствования общего программного обеспечения (ОПО) упрощался той особенностью, что всё ОПО поставлялось с исходными кодами.

Указанная ситуация привела к практическому прекращению собственных разработок в ИТ-сфере и к активному следованию западным образцам. При этом шло активное внедрение стандартов и методов разработки программного обеспечения, принятых в ряде западных стран. Однако при этом были получены и некоторые плюсы. Профессия программиста стала массовой, были подготовлены преподавательские кадры в ведущих учебных заведениях, развернута система технической поддержки на всей территории страны.

Однако, подобное решение, несмотря на отдельные плюсы и тактический выигрыш, в стратегическом отношении вел в тупик.

Нужно также вспомнить некоторые события того же периода, которые очень напоминают текущую ситуацию в ИТ-сфере в нашей стране.

В конце 70-х годов прошлого века государственные органы нашей страны довольно активно контактировали с мировым лидером ИТ-сферы того периода - компанией ИБМ. При этом компания прекрасно знала, что все программное обеспечение, которые она поставляла в СССР и в страны Восточной Европы, «заимствуется» и «адаптируется» под наши компьютеры, которые тогда обеспечивали стопроцентную совместимость с «оригинальными» компьютерами серии IBM/360 (а после и IBM/370). Однако, учитывая тот факт, что поставка крупных компьютеров попадала под ограничения КОКОМ, компания ИБМ начала продвигать на рынке серию малых компьютеров IBM Series/1 (еще не персоналок, а скорее мини-ЭВМ). Активно проводились переговоры о приобретении значительного числа этих компьютеров в интересах решения плановых и финансовых задач в органах государственной власти.

Для изучения возможностей этих машин нашими специалистами, компания ИБМ предоставила на годовые испытания один такой компьютер в один из наших открытых научно-исследовательских институтов. Понятно, что в работе над изучением возможностей этой новой системы «неофициально» привлекались ведущие специалисты других институтов, входящих в состав организаций ВПК. Эта работа началась в конце 1979 года, но уже в марте 1980 года была практически остановлена. Причина - «бойкот» со стороны западных стран Московской Олимпиады-80. Компания ИБМ (в лице ее специалистов) до этого заверяла всех, что в основе ее деятельности лежат только экономические интересы - никакой политики. Однако в марте 1980 года представительство компании ИБМ в полном составе уехало из нашей страны в соответствии с рекомендациями Госдепартамента США. А если учесть тот факт, что специально для проведения Олимпиады-80 были закуплены два больших компьютера IBM/370-148 (с условиями использования в последующем для нужд городского хозяйства Москвы, что позволило обойти ограничения КОКОМ), то отъезд всех технических специалистов, которые могли обеспечить качественное сопровождение этих компьютеров, поставил под сомнение политику неучастия компании ИБМ в политике.

К счастью, наши отечественные специалисты успешно справились со всем поставленными вызовами, и, ИТ-сопровождение Московская
Олимпиады-80 прошло без какихлибо сбоев. Но, как говорится, «осадочек остался», хотя спустя несколько месяцев представительство компании ИБМ возобновило свою работу в Москве. Именно после этих событий, которые показали всю опасность «слепой ориентации» на западные образцы, в нашей стране начались активные разработки отечественных программных средств, в частности, разработка отечественных систем управления базами данных. Конечно, они тоже были ориентированы на использование компьютеров типа ЕС ЭВМ (аналог IBM/370), но в основе уже лежали полностью отечественные программные решения. Среди них стоит отметить систему управления базами данных «Информационная система для ЕС ЭВМ (СУБД ИНЕС)», авторы которой Арлазаров В. Л. и Емельянов Н. Е. через 9 лет были удостоены Премии Совета Министров СССР. Несмотря на то, что системы ИНЕС первоначально разрабатывалась на ЕС ЭВМ, заложенные в ней решения позволяли обеспечить ее потенциальную трансформацию на любую другую платформу. Этот факт получил подтверждение в последующие годы, когда в середине 90-х годов в Институте Системного Анализа РАН (до 1992 г. - ВНИИСИ, в котором работал один из авторов ИНЕС Емельянов Н.Е.) была разработана СУБД «НИКА» является наследницей СУБД «ИНЕС», работавшей на больших машинах серии ЕС ЭВМ. Она уже могла эксплуатироваться на компьютерах интеловской архитектуры.

Именно в 80-х годах в нашей стране аактивно проводились работы по разработке и адаптации различных СУБД и информационно-поисковых систем. Сейчас становится очевидным, что в тот период времени отечественные разработки находились в худшем положении, чем адаптированные «заимствованные» западные продукты, которые не требовали масштабного финансирования необходимого для собственных решений.

В середине 80-х годов прошлого века к нашим специалистам в сфере ИТ пришло понимание того, что путь 
«слепого» копирования западных образцов ведет в потенциальный тупик, но время для принятия соответствующих решений было упущено - в 1991 году мы все оказались в новой реальности и в новой стране.

Есть старый афоризм (авторство приписывают и Платону, и Ломоносову) - «кто забывает прошлое, тот не имеет будущего». И, возможно, следует взглянуть на проблему импортозамещения в ИТ-сфере с учетом полученного ранее отрицательного опыта.

Попытки отхода от использования продукции Майкрософт (которая в конце 90-х годов заняла место, ранее занимаемое компанией ИБМ) начались в нашей стране в начале 2000-х. Этому способствовали страшилки типа «проблема 2000», когда пришло понимание того факта, что отсутствие исходных кодов операционных систем и СУБД делает нас потенциально уязвимыми для любых угроз подобного рода. В эти годы в Министерстве информатизации и связи (ныне Министерство связи и массовых коммуникаций) в 2001 году была создано подразделение, активно занимавшееся попытками внедрения открытого программного обеспечения в деятельность по информатизации органов государственной власти. Однако уже к 2004 году, когда стало ясно, что эту проблему нельзя решить с наскока, это подразделение было ликвидировано без всякого правопреемника. Через пять лет ситуация повторилась. В декабре 2010 года вышло распоряжение Правительства Российской Федерации №2299-р об утверждении плана перехода федеральных органов исполнительной власти и федеральных бюджетных учреждений на использование свободного программного обеспечения в срок до 2015 года. Это распоряжение постигла та же «печальная» судьба, как и многие другие (по крайней мере имеющие отношение к ИТ-сфере). Прошло еще пять лет, и мы снова стоим перед той же проблемой.

Рассмотрим нынешние предложения по созданию отечественной программной платформы. Большая часть предлагаемых вариантов базируется на решениях, лежащих в основе Linux. Основной довод - это свободно распространяемое ОПО, у которого есть исходные коды. Эти коды позволяют обеспечит отказ от проприетарных решений, предлагаемых западными производителями и обеспечить нашу технологическую независимость.

Однако, не следует забывать, что в основе любых дистрибутивов Linux, лежит единое ядро, разработка которого проводится «энтузиастами», поддерживаемые консорциумом Linux Foundation, в котором трудится и автор Linux - Линус Торвальд. Интересно, что указанный консорциум существует за счет спонсоров, в число которых входят такие известные компании, как Hewlett Packard, IBM, Oracle, Intel, AMD, Cisco, а не менее известная компания Microsoft объявила об установлении партнёрских отношений с Linux Foundation. Сравните перечень этих компаний с перечнем основных производителей программного обеспечения, которое мы собираемся «импортозамещать». Не окажемся ли мы в том же положении, как и 50 лет назад, когда мы взяли исходные коды и построили на них всю ИТ-сферу тех времен?

Возможно, следует более внимательно обратить внимание на опыт Китая, который также начал с Linux, а затем уплыл от него в собственном направлении.

Также следует задуматься и об аппаратной платформе, об импортозамещении которой говорят немного меньше. Однако, здесь уже есть некоторые решения, в частности, проект «Эльбрус». Так ФГБУ НИИ «Восход» закупает 22 сервера на базе «Эльбрус-4» для использования в составе государственных информационных систем. Пенсионный фонд России также проводил испытания указанных систем для решения своих задач. Есть и другие примеры, но пока это отдельные шаги в направлении импортозамещения. Несмотря на то, что характеристики этих моделей на несколько лет отстают от последних западных образцов, однако есть и существенное преимущество - частичное решение вопросов обеспечения информационной безопасности за счет отечественной архитектуры. Ясно сейчас только одно - быстрого и одномоментного решения, подобного тому, что было принято 50 лет назад, нет. Отсутствие единственного представителя от государства, через которого должна осуществляться координация работ в этой области, сейчас тоже нет. Предложенные решения, типа создания реестра отечественных программных средств для органов государственной власти, это тактические решения, применимые для ограниченного круга задач.

\section{3. Заключение}

Понятно, что процесс импортозамещения в ИТ-сфере рассчитан на несколько лет, но если не будет выработана государственная политика в импортозамещения в ИТ-системах, не будут выделены ведущие государственные институты, координирующие этот процесс, и не будет организована подготовка кадров для решения этой программ, то результат скорее всего будет не слишком впечатляющим.

При этом последний вопрос, а именно КАДРЫ, может оказаться решающим. Нынешний подход к импортозамещению может рассматриваться как первый (или даже подготовительный) этап длительной и серьезной работы. Существующая сейчас система подготовки специалистов в этой сфере не ориентирована на решение проблем импортозамещения в будущем, она ориентирована на обеспечение ближайших потребностей экономики и производства. И без кардинальных усилий со стороны государства по модернизации системы образования в ИТ-сфере мы не сможем перейти к последующим этапам решения задачи импортозамещения в сфере информационных технологий.

\section{Литература}

1. Об утверждении Плана перехода федеральных органов исполнительной власти и федеральных бюджетных учреждений на использование свободного программного обеспечения на 2011-2015 год. Распоряжение Правительства Российской Федерации от 17 декабря 2010 г. № 2299-p. 
2. Андрианова Е.Г., Сычева А.И., Багров С.В. Пути обеспечения безопасности функционирования распределённых информационных систем государственного и муниципального управления // ИТ-Стандарт. 2014. Т. 1. № 1-1 (1). с. 52-54.

3. Лямин Ю.А. Проблемы использования импортных программных комплексов при мониторинге информационных систем. // Интеллектуальные системы в информационном противоборстве. Труды конференции. - М.: РЭУ им. Плеханова, 2015, c. 145-149

4. Массух И. Импортозамещение программного обеспечения: хорошо забытые старые задачи. Экспертный центр электронного государства. Сентябрь 2015. http://drussia.ru/wp-content/uploads/2015/09/ RMI_3_SC.pdf

\section{References}

1. Ob utverzhdenii Plana perekhoda federal'nykh organov ispolnitel'noi vlasti i federal'nykh byudzhetnykh uchrezhdenii na ispol'zovanie svobodnogo programmnogo obespecheniya na 2011-2015 god.Rasporyazhenie Pravitel'stva Rossiiskoi Federatsii ot 17 dekabrya 2010 g. № 2299-r.

2. Andrianova E. G., Sycheva I. A., Bagrov S. V. ways of ensuring security of functioning of the distributed information systems of state and municipal management // IT-Standard. 2014. T. 1. № 1-1 (1). C. 52-54.

3. Lyamin Y. A. Problems of using foreign software complexes for monitoring of information systems. // Intellectual systems in the information confrontation. Proceedings of the conference. - M.: REU, 2015, c. 145-149.

4. Massukh I. Importozameshchenie programmnogo obespecheniya: khorosho zabytye starye zadachi. Ekspertnyi tsentr elektronnogo gosudarstva. Sentyabr' 2015. http://drussia.ru/wp-content/uploads/2015/09/ RMI_3_SC.pdf 